\title{
Batch Mode Reactor for 3,5-Dinitrosalicylic Acid Degradation by Phanerochaete chrysosporium
}

\author{
Rafał Madaj $^{1}\left(\mathbb{D}\right.$, Witold Sroczyński $^{2}{ }^{,}$Michał Sójka $^{3}$, Tomasz P. Olejnik ${ }^{3}$ (D) and Elżbieta Sobiecka ${ }^{2, *}$ \\ 1 Centre of Molecular and Macromolecular Studies, Polish Academy of Sciences, Sienkiewicza 112, \\ 90-363 Lodz, Poland; rmadaj@cbmm.lodz.pl \\ 2 Institute of Natural Products and Cosmetics, Faculty of Biotechnology and Food Sciences, \\ Lodz University of Technology, Stefanowskiego 4/10, 90-924 Lodz, Poland; witold.sroczynski@p.lodz.pl \\ 3 Institute of Food Technology and Analysis, Lodz University of Technology, Stefanowskiego 4/10, \\ 90-924 Lodz, Poland; michal.sojka@p.lodz.pl (M.S.); tomasz.olejnik@p.lodz.pl (T.P.O.) \\ * Correspondence: elzbieta.sobiecka@p.lodz.pl; Tel.: +48-42-6313411
}

check for updates

Citation: Madaj, R.; Sroczyński, W.; Sójka, M.; Olejnik, T.P.; Sobiecka, E. Batch Mode Reactor for 3,5-Dinitrosalicylic Acid Degradation by Phanerochaete chrysosporium. Processes 2021, 9, 105. https:// doi.org/10.3390/pr9010105

Received: 2 December 2020 Accepted: 31 December 2020 Published: 6 January 2021

Publisher's Note: MDPI stays neutral with regard to jurisdictional clai$\mathrm{ms}$ in published maps and institutional affiliations.

Copyright: (C) 2021 by the authors. Licensee MDPI, Basel, Switzerland. This article is an open access article distributed under the terms and conditions of the Creative Commons Attribution (CC BY) license (https:// creativecommons.org/licenses/by/ $4.0 /)$.

\begin{abstract}
A new batch mode reactor was constructed to conduct continuous biodegradation of 3,5-dinitrosalicylic acid. Various types of matrices with immobilized Phanerochaete chrysosporium were immersed in a solution containing pollutant and mineral nutrients. Three parameters were chosen to optimize the process. The nitrate and nitrite ions concentrations and HPLC analysis were used to prove the biodegradation of 3,5-dinitrosalicylic acid, and the mixed effects model using one-factor ANOVA was used for statistical calculations. The results showed the correlation between the initial $\mathrm{pH}$, a medium composition, and the process time. In $\mathrm{pH}=6.5$, the degradation effectiveness was estimated at $99 \%$ decrease in the substrate within 14 days, while an $80 \%$ decrease of acid concentration was indicated in $\mathrm{pH}=3.5$ after 28 days of the process duration.
\end{abstract}

Keywords: the 3,5-dinitrosalicylic acid; Phanerochaete chrysosporium; biodegradation; batch reactor

\section{Introduction}

Nitroaromatic compounds have been produced and used primarily as explosives materials for many years [1]. The presence of $-\mathrm{NO}_{2}$ groups determine their high toxic and cancerogenic properties [2]. 3,5-Dinitrosalicylic acid (3,5-DNS acid) classified as a hazardous waste and listed in the European Catalogue on Hazardous Waste with the codes 06.01.06 and 06.10.02.3 is one of the representatives of this chemical group [3]. 3,5-DNS acid has been used for years as the main reagent in laboratories for the analysis of sugars in reducing reactions [4]. The improper storage and utilization of 3,5-DNS acid influences environmental pollution.

To minimize the contamination effect of nitroarenes on the environment, several methods were proposed. They were based on physicochemical and chemical reactions with hydrogen peroxide or ozone, Fenton's reagent in oxidation or UV radiation, incineration, or sonolysis [5-9]. These processes are often supported by physical treatments like coagulation, adsorption, or filtration [10]. The chemical and physicochemical methods have limited efficiency and generate a high cost of utilization. Nevertheless, there is a group of microorganisms which developed metabolic pathways for degradation of these pollutants. The white rot fungi to which Phanerochaete chrysosporium has been classified produces enzymes that are able to decompose nitroaromatic compounds including 3,5-DNS acid. They can reduce nitro group to the amine derivative as well as divide the aromatic ring to the aliphatic chain via enzymatic oxidation $[11,12]$.

The aim of our research is to present a new process of 3,5-dinitrosalicylic acid degradation by Phanerochaete chrysosporium in a batch reactor that works at a micro-industrial scale. The scientific literature reports that nitrocompounds, including 3,5-DNS acid, biodegrade in stationary culture conditions. Our research allows for the improvement of biodegradation efficiency as well as a reduction in time for the process. 


\section{Materials and Methods}

\subsection{Materials}

\subsubsection{Biological Material}

The microorganisms used in our research were Phanerochaete chrysosporium Burdsall ATCC 34,511, which originated from the Lodz Centre Culture Collection (LOCK) and were deposited in the Institute of Molecular and Industrial Biotechnology at Lodz University of Technology.

The basidiomycete was inoculated and stored on the 3\% agar maltose slants enriched with $5 \mathrm{wt} \%$ of oat meals. Two weeks before starting the experiment, the strain was activated in a wort medium (peptones $15 \mathrm{~g} / \mathrm{dm}^{3}$, yeast extract $3 \mathrm{~g} / \mathrm{dm}^{3}, \mathrm{NaCl} 6 \mathrm{~g} / \mathrm{dm}^{3}$, and $\mathrm{D}(+)$ glucose $1 \mathrm{~g} / \mathrm{dm}^{3}$ ) in the temperature $37^{\circ} \mathrm{C}$ for one week in aerobic condition. Next, $5 \mathrm{~cm}^{3}$ of the Phanerochaete chrysosporium inoculum (OD $660=0.3$ ) was added to each flask to allow the biomass to grow before starting the flow culture experiment.

\subsubsection{Immobilization Matrices}

The matrices used in the continuous flow cultures for biomass immobilization were as follows:

- Beech smoking chips of BROWIN Company, Poland, consisting of cellulose (41 wt $\%$ ), hemicellulose (33 wt \%), lignin (22\% wt \%), and other substances (4wt\%) [13];

- Sugar beet pulp originating from sugar beet processes as the by-products used in the form of a briquette which comprises carbohydrates (75 wt\%) and nitrogen (9 $\mathrm{wt} \%)$ [14]; and

- Polyurethane foam-block samples at sizes $1 \mathrm{~cm}^{3} \times 1 \mathrm{~cm}^{3} \times 1 \mathrm{~cm}^{3}$ of polyether polyol foam (EUROFOAM Company). The polyurethane foam was free of nutrients. To prepare the culture condition which could be compared to the samples including the other matrices, it was necessary to enrich this culture with the source of polysaccharides. The citrus peels were chosen as a natural source of dietary fibres (about $\left.65 \mathrm{wt}^{\mathrm{t}} \%\right)[15,16]$.

The Erlenmeyer's flasks were filled up with $60 \% v / v$ matrices and soaked up in the water $(40 \% v / v)$. After sterilization $\left(20 \mathrm{~min}\right.$ in $121^{\circ} \mathrm{C}$ under a pressure of $\left.0.1 \mathrm{MPa}\right), 5 \mathrm{~cm}^{3}$ of the Phanerochaete chrysosporium inoculum (OD $660=0.3$ ) was added to each flask to initiate the biomass growth before starting the flow culture experiment. The incubation lasted 6 weeks in a temperature of $37^{\circ} \mathrm{C}$ in aerobic condition.

\subsubsection{The 3,5-Dinitosalicylic Acid}

3,5-dinitrosalicylic acid (3,5-DNS) from Sigma-Aldrich (St. Louis, MO, USA) was used in our research. Its CAS number was $609-99-4$, and the purity was $98.4 \%$.

\subsection{Methods}

\subsubsection{Continuous Culture Condition}

The biodegradation process was conducted at a micro-industrial scale in the batch reactor (Figure 1) [17]. At the beginning, the peristaltic pump (2) was started by dispensing the liquid dose onto the immobilizing matrix containing microorganisms. The matrix was placed into the reactor (vessel 1) with a nominal capacity of $100 \mathrm{~cm}^{3}$. 


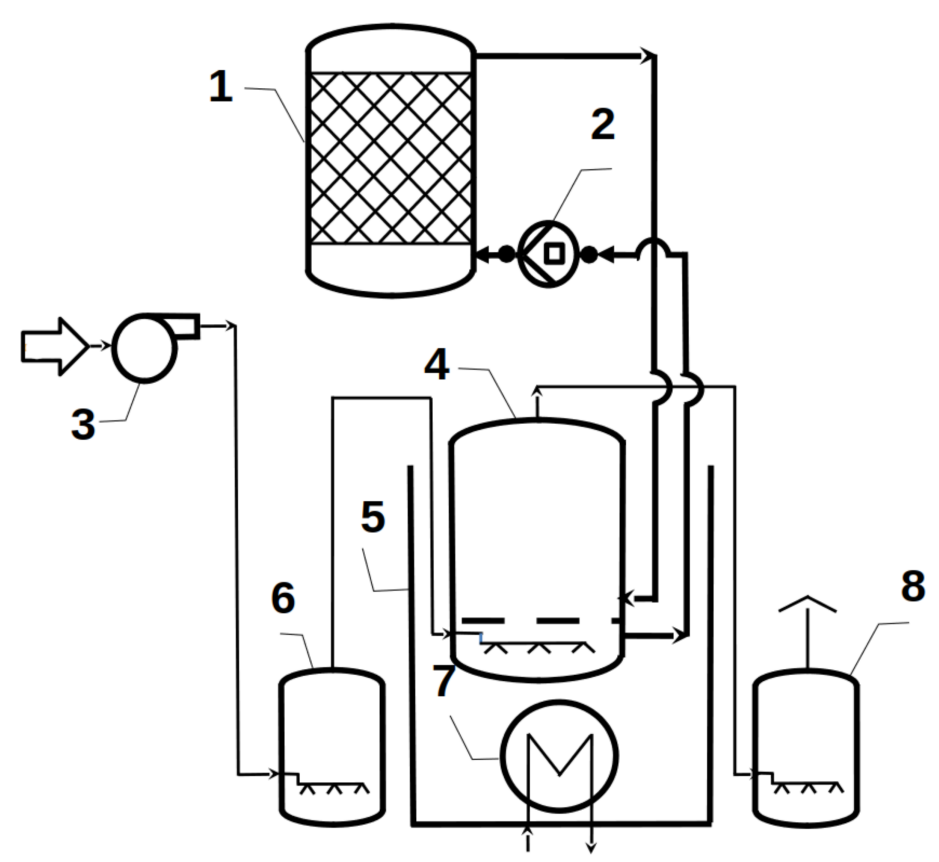

Figure 1. The bioreactor used in our studies: 1-reactor's main chamber (vessel), 2-peristaltic pump, 3-aerator, 4-media container, 5-water bath, 6-inlet scrubber, 7-heating element, and 8-outlet scrubber.

Simultaneously, four $500 \mathrm{~cm}^{3}$ containers (4) were filled with the chosen liquid media (regular or enriched with mineral salts). The containers were placed in a water bath while maintaining a constant temperature of $37^{\circ} \mathrm{C}$. Then, after 6 weeks of immobilizing microorganisms, the peristaltic pump (2) supplied the medium from reactor (vessel) (1) to the container (4) at initial volumetric flow equals $1.4 \times 10^{-4} \mathrm{dm}^{3} / \mathrm{s}$. During the experiments, the flow output was maintained at the same rate. In addition, an aerator (3) was used to allow conduction of the process under aerobic conditions at both ports of the reactor at the inlet (6) and outlet (8), respectively. The potassium manganate (VII) solution with a concentration of $1 \mathrm{~mol} / \mathrm{dm}^{3}$ was used to hold the air sterility.

Two types of media were applied during the experiment. The first medium (A) consisted of distilled water, $0.1 \% v / v$ of the $3,5-\mathrm{DNS}$ acid with the concentration of 4.0 $\times 10^{-3} \mathrm{~mol} / \mathrm{dm}^{3}$, and $5.0 \times 10^{-2} \mathrm{~mol} / \mathrm{dm}^{3}$ citric buffer which allowed for starting the cultures in various $\mathrm{pH}$ conditions: $3.5,4.5,5.5$, or 6.5 . The studies also considered three immobilization matrices as the experimental samples: A1-medium A flowing beech smoking chips; A2-medium A flowing a sugar beet pulp; and A3-medium A flowing a polyurethane foam. The second medium solution (B) used in the process consisted of the first medium (A) supplemented by the modified Czapek medium [18]. The potassium nitrate was substituted by $1.0 \mathrm{~g} / \mathrm{dm}^{3}$ ammonium sulphate. Additionally, the glucose solution with an approximate concentration of $3.2 \mathrm{~g} / \mathrm{dm}^{3}$ was added. The samples of this experimental part were B1-medium B flowing the beech smoking chips; B2-medium B flowing a sugar beet pulp; and B3-medium B flowing a polyurethane foam. After 28 days, the process was stopped and the liquid samples were collected for chemical analyses.

\subsubsection{Chemical Analysis}

Every seven days, the samples were collected for chemical analysis. The $\mathrm{pH}$ measurements were done using the Elmetron CP-505 pH-meter with temperature compensation. The nitrate and nitrite ions concentrations were measured using QUANTOFIX test straps at the concentration ranges $10-500 \mathrm{mg} / \mathrm{dm}^{3}$ of $\mathrm{NO}_{3}{ }^{-}$and $1-80 \mathrm{mg} / \mathrm{dm}^{3}$ of $\mathrm{NO}_{2}{ }^{-}$. 
The High-Performance Liquid Chromatography (HPLC) Analysis of 3,5-DNS Acid

The samples were subjected to liquid-liquid extraction against ethyl acetate (analytical grade, $\mathrm{POCH}$ ) three times in 2:1 liquid-extractant ratio. Then, the extract was evaporated under a vacuum and dissolved in acetonitrile (HPLC grade, SIGMA-ALDRICH). The extracted 3,5-DNS acid was analysed using a Dionex 5110 with C18 RP Phenomenex $250 \mathrm{~mm} \times 4.60 \mathrm{~mm} \times 5 \mu \mathrm{m}$ column with a detector Dionex UVD $340 S$ set to $\lambda=210 \mathrm{~nm}$. Mobile phase (isocratic conditions) consisted of $0.1 \%$ acetic acid solution (HPLC grade, SIGMA-ALDRICH) of ultrapurified water and acetonitrile (HPLC, SIGMA-ALDRICH) in a 30:70 ratio.

\subsection{Statistical Calculations}

The statistical calculations and presentation of the results were done using Statictica 12 (StatSoft, Tulsa, OK, USA).

\section{Results and Discussion}

To optimize the process, we focused on three factors: the type of immobilization matrix, the mineral composition of the liquid media, and the initial culture acidity $(\mathrm{pH})$.

The results obtained in our research proved that the initial composition of the process medium and its initial acidity significantly influenced the biodegradation effect (Figure 2). In strongly acidic conditions $(\mathrm{pH}=3.5)$, the degradation process was not effective within the investigated time while an initial $\mathrm{pH}$ higher than 4.5 intensified the process. The most effective decomposition of 3,5-DNS acid (over 90\%) was observed at the second week of the process in the samples with initial pHs 5.5 and 6.5. The results showed that the type of immobilization matrix did not determine the process effectiveness significantly.
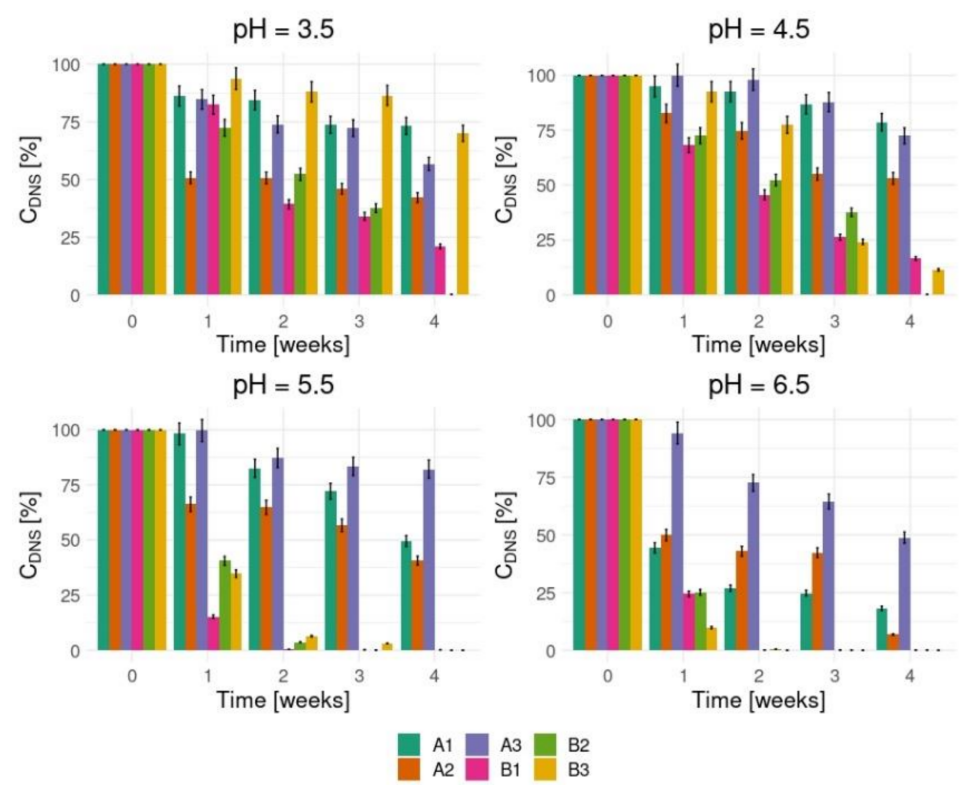

Figure 2. The 3,5-dinitrosalicylic acid (3,5-DNS acid) decrease after biodegradation process.

In our previous research concerning 3,5-DNS acid biodegradation by Phanerochaete chrysosporium in stationary condition cultures, the substrate's concentration decreased after the third week of the process [19]. The most effective degradation level did not exceed $55 \%$ of the initial concentration of 3,5-DNS acid $\left(8 \times 10^{-4} \mathrm{~mol} / \mathrm{dm}^{3}\right)$.

To prove 3,5-DNS acid is decomposed by basidiomycetes, we started with the identification of nitrate and nitrite ions that should appear in the medium solution during biodegradation. Figures 3 and 4 show the tests results which confirm high both nitrate and nitrite ions concentrations levels in the enriched medium cultures in which the initial $\mathrm{pHs}$ were 5.5 and 6.5 . 

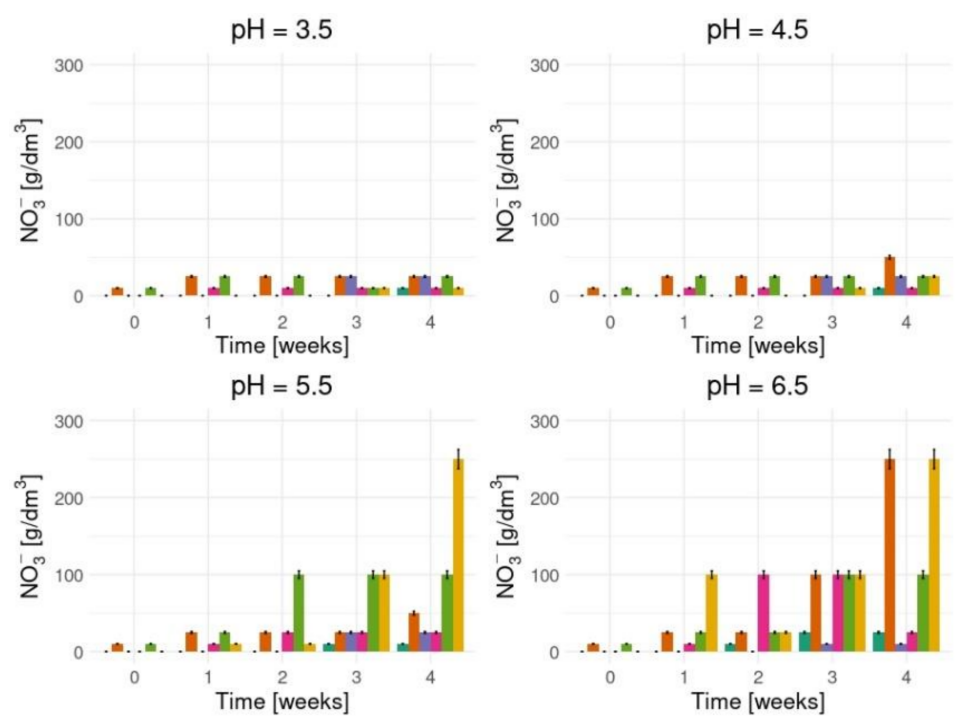

$\begin{array}{lll}A 1 & \text { A3 } & B 2 \\ A 2 & B 1 & B 3\end{array}$

Figure 3. The nitrate ions concentration levels in various process conditions.
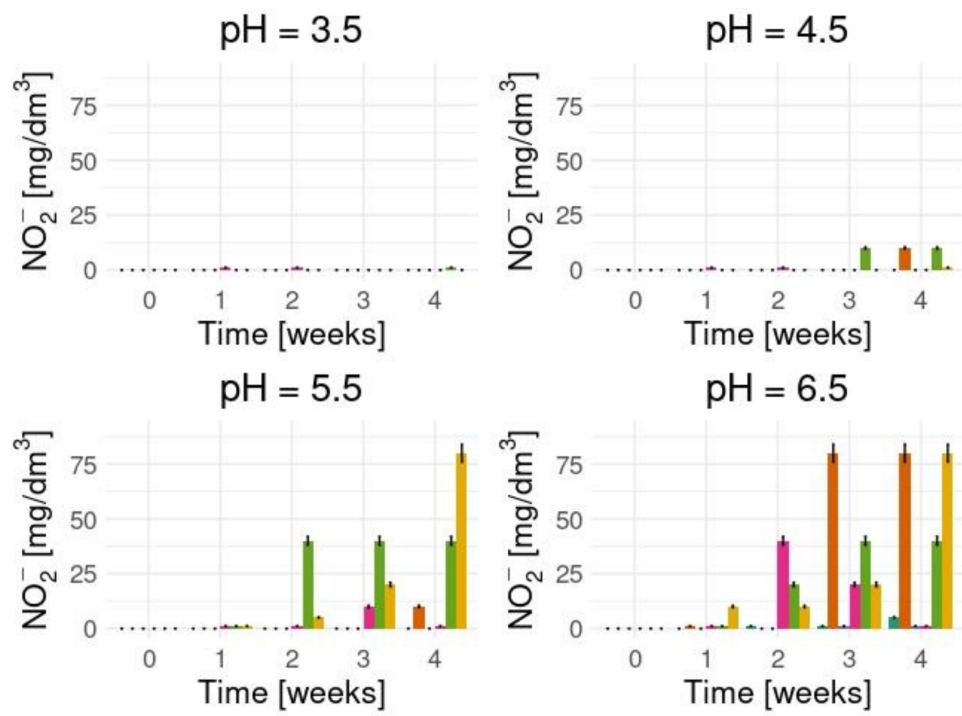

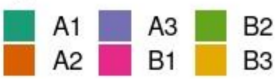

Figure 4. The nitrite ions concentration levels in various process conditions.

The HPLC analyses confirmed the presence of intermediate products of 3,5-DNS acid (1) which appeared during the enzymatic decomposition (Table 1).

There were two possibilities of the 3,5-DNS acid initial decomposition (Figure 5): by $\mathrm{C} 1$ ring decarboxylation or by the reduction of the $-\mathrm{NO}_{2}$ group linked to $\mathrm{C} 3$ in an acid molecule [20]. The by-products that appeared were 3-amino-5-nitrosalicylic acid (2) and 2,4dinitrophenol (3). The 2-amino-4-nitrophenol appeared as the third common by-product (4). Next, the nitro groups linked to $C 5$ and $C 6$ were replaced by the hydroxyl groups which caused the appearance of the 1-amino-2,4,5-trihydroxybenzene (5). The next step in the enzymatic oxidation was ring decomposition to the aliphatic chain by-products. 
Table 1. The compounds identified during various stages of 3,5-DNS acid biodegradation.

\begin{tabular}{cccc}
\hline No & $m / z$ & Retention Time [min] & Name of Substrate and by Products \\
\hline 1 & 227 & 1.86 & the 3,5-dinitrosalicylic acid \\
2 & 197 & 2.74 & the 3-amino-5-nitrosalicylic acid \\
3 & 183 & 2.16 & the 2,4-dinitrophenol \\
4 & 153 & 2.24 & the 2-amino-4-nitrophenol \\
5 & 141 & 2.31 & the 1-amino-2,4,5-trihydroxybenzene \\
\hline
\end{tabular}

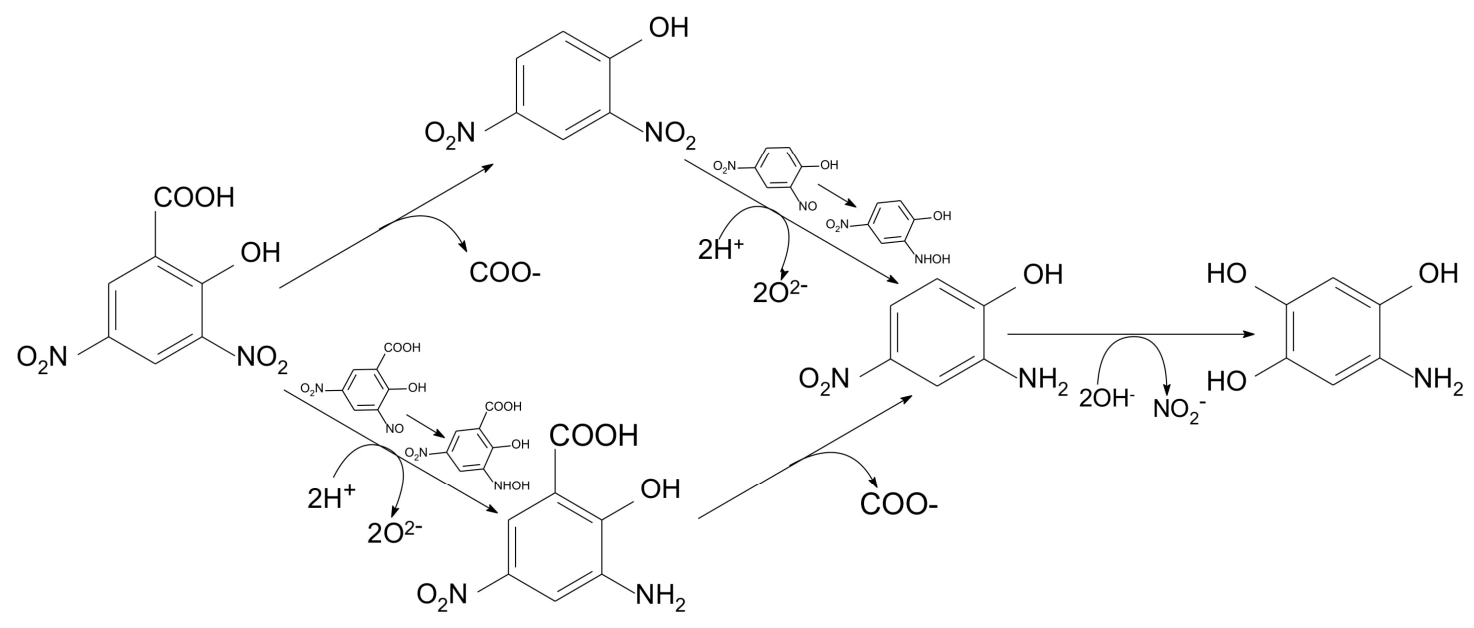

Figure 5. The 3,5-disalicilic acid degradation pathway Phanerochaete chrysosporium.

The enzyme system of Phanerochaete chrysosporium characterized by broad spectrum enzyme production consisted of membrane-bound cyto-chrome P450-related proteins, dioxygenases, nitrobenzene nitroreductase (E.C. 1.7.1.16), lignin peroxidase LiP (E.C. 1.11.1.14), manganese-dependent peroxidase MnP (E.C. 1.11.1.13), and laccase (E.C.1.10.3.2) that catalyse the decomposition of chloropesticides, nitroarenes, or aryl alcohols [21-24]. Lignin peroxidase (LiP) synthesized by Phanerochaete chrysosporium is one of the enzymes directly involved 3,5-DNS acid biodegradation which dominated in the first stages of molecule oxidation by 3-amino-5-nitrosalicylic acid or 2,4-dinitrophenol to obtain 2-amino4-nitrophenol.

The process was intensified by the presence of nutrients in the culture medium such as cellulose and hemicelluloses as well as aromatic alcohols that may have been released through the breakdown of lignin [25]. The alcohols could slow down the catalytic decomposition of 3,5-DNS acid due to the co-substrates of enzymes degrading nitrocompounds. The presence of $\mathrm{Mn}(\mathrm{II})$ ions influenced biomass growth as well as manganese-dependent peroxidase $(\mathrm{MnP})$ and lignin peroxidase (LiP) synthesis and their activities [26,27].

In order to confirm the hypothesis concerning the influence of three chosen parameters on 3,5-DNS acid biodegradation, statistical calculations were also performed. The firstorder (noninteractive) ANOVA main effects analysis as well as the post-hoc Duncan's test were used. The results proved that the medium composition, the initial $\mathrm{pH}$, and the type of matrix significantly influenced the changing substrate concentrations during the process (Figure 6).

The chemical analyses and statistic calculations proved that parameters like the type of immobilization matrix, the mineral composition of the liquid media, and the initial $\mathrm{pH}$ caused high process effectiveness conducted in the batch reactor. 

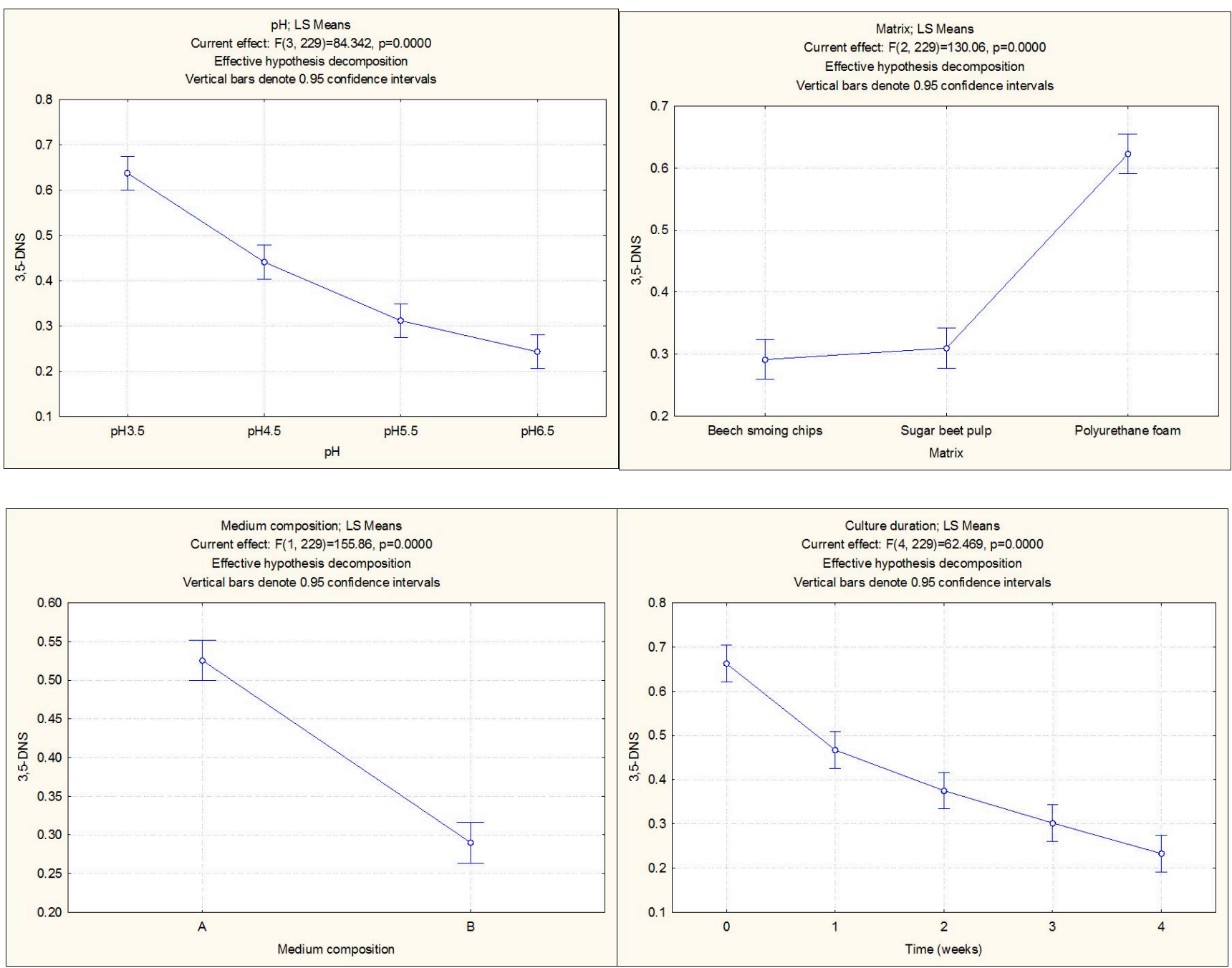

Figure 6. Graph of statistical analysis (ANOVA) of the tested parameter influences ( $\mathrm{pH}$, matrix, medium composition, and time) on 3,5-DNS acid concentration.

\section{Conclusions}

The results obtained in our research proved that Phanerochaete chrysosporium is able to degrade 3,5-dinitrosalicylic acid. Phanerochaete chrysosporium was able to decompose 3,5-dinitrosalicylic acid under proper conditions to fully degrade a $4 \times 10^{-3} \mathrm{~mol} / \mathrm{dm}^{3}$ solution of the substrate within 14 days. The reactor was operated in aatch mode until the assumed reduction of the 3,5-dinitrosalicylic acid was achieved.

All the tested parameters (the mineral composition, the initial $\mathrm{pH}$ of the cultures, as well as the type of immobilization matrix) were important for efficient biodegradation. The most effective results of the biodegradation in a batch mode reactor working at a microindustrial scale guaranteed the culture condition in the enriched medium with an initial $\mathrm{pH}$ of 6.5 with microorganisms immobilized on the sugar beet pulp and the polyurethane foam. The obtained results are fundamental for implementing the process on the industrial scale and for application in wastewater treatment.

Author Contributions: Conceptualization, R.M. and E.S.; methodology, R.M. and E.S.; software, M.S. and R.M.; validation, M.S. and R.M.; formal analysis, R.M., M.S., and W.S.; investigation, R.M.; resources, R.M. and E.S.; writing—original draft preparation, E.S., R.M., and T.P.O.; writing-review and editing, E.S. and T.P.O.; visualization, E.S. and R.M.; supervision, E.S.; project administration, R.M. and E.S. All authors have read and agreed to the published version of the manuscript. 
Funding: This research received no external funding.

Institutional Review Board Statement: Not applicable.

Informed Consent Statement: Informed consent was obtained from all subjects involved in the study.

Data Availability Statement: The data presented in this study are available on request from the corresponding author. The data are not publicly available due to the internal founding research of co-authors in their affiliation places.

Conflicts of Interest: The authors declare no conflict of interest.

\section{References}

1. Williams, M.; Reddy, G.; Quinn, M.; Johnson, M. Wildlife Toxicity Assessments for Chemicals of Military Concern; Elsevier BV: Amsterdam, The Netherlands, 2015; pp. 25-51.

2. Gong, P.; Kuperman, R.G.; Sunahara, G.I. Genotoxicity of 2,4- and 2,6-dinitrotoluene as measured by the Tradescantia micronucleus (Trad-MCN) bioassay. Mutat. Res. Mol. Mech. Mutagen. 2003, 538, 13-18. [CrossRef]

3. The Council Decision 2003/33/EC Establishing Criteria and Procedures for the Acceptance of Waste at Landfills Pursuant to Article 16 of and Annex II to Directive 1999/31/EC. 2003. Available online: http://data.europa.eu/eli/dec/2003/33(1)/oj (accessed on 2 December 2020).

4. Miller, G.L. Use of Dinitrosalicylic Acid Reagent for Determination of Reducing Sugar. Anal. Chem. 1959, 31, 426-428. [CrossRef]

5. Verma, P.; Baldrian, P.; Nerud, F. Decolorization of structurally different synthetic dyes using cobalt(II)/ascorbic acid/hydrogen peroxide system. Chemosphere 2003, 50, 975-979. [CrossRef]

6. Shah, M. Effective Treatment Systems for Azo Dye Degradation: A Joint Venture between Physico-Chemical \& Microbiological Process. Int. J. Environ. Biorem. Biodegrad. 2014, 2, 231-242. [CrossRef]

7. Koprivanac, N.; Vujevic, D. Degradation of an Azo Dye by Fenton Type Processes Assisted with UV Irradiation. Int. J. Chem. React. Eng. 2007, 5. [CrossRef]

8. Guivarch, E.; Trevin, S.; Lahitte, C.; Oturan, N. Degradation of azo dyes in water by Electro-Fenton process. Environ. Chem. Lett. 2003, 1, 38-44. [CrossRef]

9. Stock, N.L.; Peller, J.; Vinodgopal, A.K.; Kamat, P.V. Combinative Sonolysis and Photocatalysis for Textile Dye Degradation. Environ. Sci. Technol. 2000, 34, 1747-1750. [CrossRef]

10. Koyuncu, I.; Topacik, D.; Yuksel, E. Reuse of reactive dyehouse wastewater by nanofiltration: Process water quality and economical implications. Sep. Purif. Technol. 2004, 36, 77-85. [CrossRef]

11. Rieble, S.; Joshi, D.; Gold, M. Aromatic Nitroreductase from the Basidiomycete Phanerochaete chrysosporium. Biochem. Biophys. Res. Commun. 1994, 205, 298-304. [CrossRef]

12. Erkurt, E.A.; Ünyayar, A.; Kumbur, H. Decolorization of synthetic dyes by white rot fungi, involving laccase enzyme in the process. Process. Biochem. 2007, 42, 1429-1435. [CrossRef]

13. Vek, V.; Oven, P.; Poljanšek, I. Review on Lipophilic and Hydrophilic Extractives in Tissues of Common Beech. Drv. Ind. 2016, 67, 85-96. [CrossRef]

14. Kühnel, S.; Schols, H.A.; Gruppen, H. Aiming for the complete utilization of sugar-beet pulp: Examination of the effects of mild acid and hydrothermal pretreatment followed by enzymatic digestion. Biotechnol. Biofuels 2011, 4. [CrossRef] [PubMed]

15. Rafiq, S.; Kaul, R.; Sofi, S.; Bashir, N.; Nazir, F.; Nayik, G.A. Citrus peel as a source of functional ingredient: A review. J. Saudi Soc. Agric. Sci. 2018, 17, 351-358. [CrossRef]

16. Figuerola, F.; Hurtado, M.L.; Estévez, A.M.; Chiffelle, I.; Asenjo, F. Fibre concentrates from apple pomace and citrus peel as potential fibre sources for food enrichment. Food Chem. 2005, 91, 395-401. [CrossRef]

17. Sroczynski, W.; Madaj, R. Układ do Utylizacji Nitrowych Związków Aromatycznych. System for Utilisation of Aromatic Nitro Compounds. Grant the Polish Patent to the Application No 426744, 25 September 2020.

18. De Oliveira, S.C.; Mendes, G.O.; da Silva, U.C.; da Silva, I.R.; Júnior, J.I.R.; Costa, M.D. Decreased mineral availability enhances rock phosphate solubilization efficiency in Aspergillus niger. Ann. Microbiol. 2014, 65, 745-751. [CrossRef]

19. Madaj, R.; Kalinowska, H.; Sroczyński, W.; Szelag, J.; Sobiecka, E. Biodegradation of 3,5-dinitrosalicylic acid by Phanerochaete chrysosporium. Folia Biol. Oecologica 2018, 14, 14-22. [CrossRef]

20. Spain, J.C. Biodegradation of Nitroaromatic Compounds. Annu. Rev. Microbiol. 1995, 49, 523-555. [CrossRef]

21. Mougin, C.; Pericaud, C.; Dubroca, J.; Asther, M. Enhanced mineralization of lindane in soils supplemented with the white rot basidiomycete Phanerochaete chrysosporium. Soil Biol. Biochem. 1997, 29, 1321-1324. [CrossRef]

22. Brahushi, F.; Kengara, F.O.; Song, Y.; Jiang, X.; Munch, J.C.; Wang, F. Fate Processes of Chlorobenzenes in Soil and Potential Remediation Strategies: A Review. Pedosphere 2017, 27, 407-420. [CrossRef]

23. De, S.; Perkins, M.; Dutta, S.K. Nitrate reductase gene involvement in hexachlorobiphenyl dechlorination by Phanerochaete chrysosporium. J. Hazard. Mater. 2006, 135, 350-354. [CrossRef]

24. Podgornik, H.; Grgić, I.; Perdih, A. Decolorization rate of dyes using lignin peroxidases of Phanerochaete chrysosporium. Chemosphere 1999, 38, 1353-1359. [CrossRef] 
25. Abdel-Hamid, A.M.; Solbiati, J.O.; Cann, I.K. Insights into Lignin Degradation and its Potential Industrial Applications. Adv. Appl. Microbiol. 2013, 82, 1-28. [CrossRef] [PubMed]

26. Falade, A.O.; Nwodo, U.U.; Iweriebor, B.C.; Green, E.; Mabinya, L.V.; Okoh, A.I. Lignin peroxidase functionalities and prospective applications. Microbiology 2017, 6, e00394. [CrossRef] [PubMed]

27. Hofrichter, M. Review: Lignin conversion by manganese peroxidase (MnP). Enzym. Microb. Technol. 2002, 30, 454-466. [CrossRef] 